\title{
A new method of analyzing the local dynamical behavior of steel box girder with stiffened plates
}

\author{
Niujing Ma', a ${ }^{1}$ Zhou $\mathrm{Li}^{2, b}$ \\ ${ }^{1}$ School of Civil Engineering and Transportation, South China University of Technology, \\ Guangzhou 510640, China \\ ${ }^{2}$ China Construction Steel Structure CORP., LTD., Shenzhen 518000, China \\ amaniujing_1@163.com, b976112542@qq.com
}

\begin{abstract}
Keywords: steel box girder, stiffened plates with trapezoidal stiffeners, local dynamical behavior, parameter study, finite element modelling

Abstract. In order to study the dynamical behavior of stiffened plates of steel box girder with trapezoidal stiffeners, FE software ANSYS and its secondary development are used to build the model of the stiffened plate. The plate, transverse diaphragms and trapezoidal stiffeners are all modelled by Shell63 Element, while the deck pavement is modelled by solid plate element with 8 nodes. Detailed process of this new element and its computational procedure are exhibited. By giving the first 10 natural frequencies of the stiffened plate corresponding to both simply supported and clamped boundary conditions, the proposed method is compared with the fine analysis method of ANSYS to verify the accuracy and efficiency of this method. Some useful conclusions are drawn and these conclusions can provide reference for the dynamic design of stiffened plates.
\end{abstract}

\section{Introduction}

With the wide use of steel box girder in long-span bridges, the mechanical behavior of their stiffened plates have been drawing increasingly attention of researchers. Up to now, the research topic on stiffened plates of steel box girder has been limited to static issues [1-3] but not dynamic problems which appear more significant to some extent, since the action on stiffened plates mainly comes from traffic dynamic loads.

There have been quantities of publications on dynamics of stiffened plates so far [4-6], however, most of these research findings are focused on normal sections of stiffeners like the rectangular section. Actually, the cross-section style of a stiffener may be diverse in different cases, this assumption is probable unreasonable and may result in huge computational errors. On the contrary, FEM is a both accurate and efficient method which can overcome this type of defect.

In this paper, FE software ANSYS and its secondary development are used to build the model of the common stiffened plate of steel box girder. The plate, transverse diaphragms and trapezoidal stiffeners are all modelled by Shell63 Element, while the deck pavement is modelled by Solid Plate Element with 8 nodes. The proposed method is compared with the fine analysis method of ANSYS so as to verify the accuracy and efficiency of this method. Some useful conclusions are drawn and these conclusions can provide reference for the dynamic design of stiffened plates.

\section{Finite element model of steel box girder with stiffened plates}

Structural description and parametric explanation. Fig. 1 shows a common steel box girder with trapezoidal stiffened plates. In the following computation, the plate and its stiffeners are made of the same material, and trapezoidal stiffeners are arranged along $x$-direction.The Nomenclature is as follows: $a$ and $b$ are the lengths in $x$-direction and $y$-direction, respectively; $\rho, E$, and $\mu$ are the mass density, Young's modulus and Poisson ratio of the stiffened plate, respectively; $t_{p}$ is the thickness of plate; $h_{s x}$ is the depth of trapezoidal stiffeners; $t_{r}$ is the thicknesses of trapezoidal stiffeners; $b_{1}$ is the spacing of trapezoidal stiffeners; $b_{2}$ is the spacing of trapezoidal stiffeners on the top; $b_{3}$ is the width of 
trapezoidal stiffeners on the bottom; $h_{s y}$ is the depth of transverse diaphragms; $\mathrm{t}_{d}$ is the thicknesses of transverse diaphragms; $a_{1}$ is the spacing of transverse diaphragms.
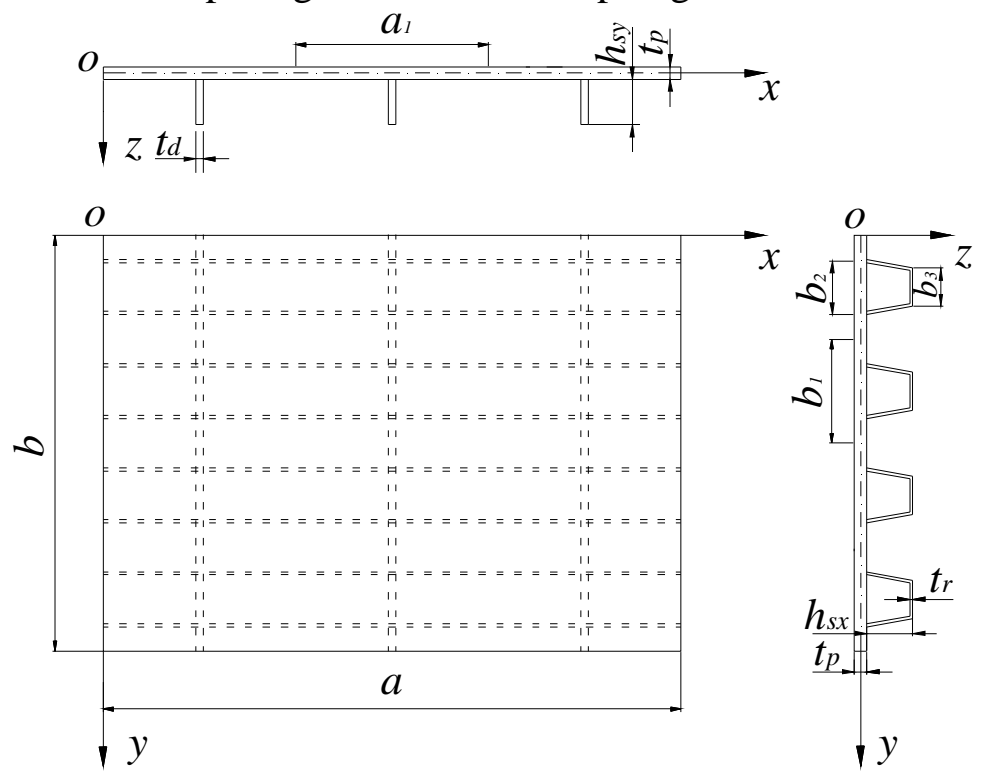

Fig.1 Structural diagram of stiffened plates with trapezoidal stiffeners of steel box girder

Types of elements for stiffened plates and deck pavement. Based on software ANSYS, Shell63 Element is used to simulate the plate, transverse diaphragms and trapezoidal stiffeners. For deck pavement, a Solid Plate Element with 8 nodes is composed to simulate deck pavement, shown in Fig.2. $t_{1}$ is the thicknesses, and $\rho_{1}$ is the mass density. Besides, each node has 5 DOFS $u, v, w$ and $\theta_{\mathrm{x}}, \theta_{\mathrm{y}}$, which can be used to represent the in-plane displacements $\Delta_{\mathrm{up}}, \Delta_{\mathrm{bp}}$ and the bending displacements $\boldsymbol{\Delta}_{\mathrm{uB}}, \Delta_{\mathrm{bB}}$ on both surfaces.

$$
\begin{aligned}
& \Delta_{\mathrm{up}}=\left[\begin{array}{lllll}
u_{1} & v_{1} & \mathrm{~L} & u_{4} & v_{4}
\end{array}\right]^{\mathrm{T}} . \\
& \Delta_{\mathrm{bp}}=\left[\begin{array}{llllll}
u_{5} & v_{5} & \mathrm{~L} & u_{8} & v_{8}
\end{array}\right]^{\mathrm{T}} . \\
& \Delta_{\mathrm{uB}}=\left[\begin{array}{llllllll}
w_{1} & \theta_{\mathrm{x} 1} & \theta_{\mathrm{y} 1} & \mathrm{~L} & w_{4} & \theta_{\mathrm{x} 4} & \theta_{\mathrm{y} 4}
\end{array}\right]^{\mathrm{T}} . \\
& \Delta_{\mathrm{bB}}=\left[\begin{array}{llllllll}
w_{5} & \theta_{\mathrm{x} 5} & \theta_{\mathrm{y} 5} & \mathrm{~L} & w_{8} & \theta_{\mathrm{x} 8} & \theta_{\mathrm{y} 8}
\end{array}\right]^{\mathrm{T}} .
\end{aligned}
$$

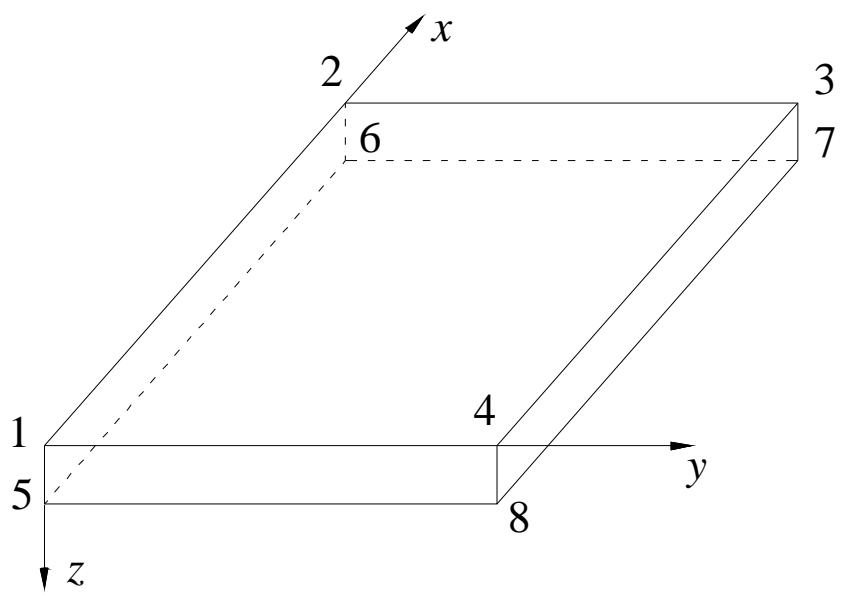

Fig.2 Eight-node solid plate element

For the displacement mode of this element, both surfaces can refer to the neutral plane of plate. For the consistent mass matrix, it can also be obtained through the similar derivation. 
Establishment of finite element model. Material and structural parameters are specified as follows: $\rho=7850 \mathrm{~kg} / \mathrm{m}^{3}, E=206 \mathrm{GPa}, \mu=0.3, a=6.4 \mathrm{~m}, b=4.8 \mathrm{~m}, a_{1}=3.2 \mathrm{~m}, b_{1}=0.6 \mathrm{~m}, b_{2}=0.3 \mathrm{~m}, b_{3}=0.18 \mathrm{~m}, h_{s x}=0.3 \mathrm{~m}$, $h_{s y}=0.6 \mathrm{~m}, t_{r}=0.008 \mathrm{~m}, t_{d}=0.012 \mathrm{~m}, t_{p}=0.016 \mathrm{~m}$. The finite element model is shown in Fig. 3 .

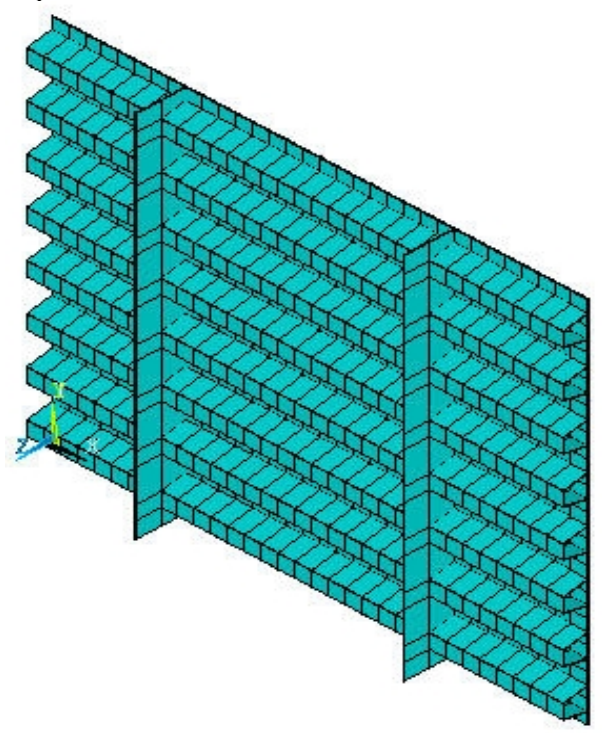

Fig.3 Finite element model of stiffened plates with trapezoidal stiffeners

Consideration of deck pavement elements. Deck pavement parameters are listed as follows: $\rho_{1}=2300 \mathrm{~kg} / \mathrm{m}^{3}, E_{1}=1.5 \mathrm{GPa}, \mu_{1}=0.35, t_{1}=0.06 \mathrm{~m}$. Application of secondary development platform for UPFs can make program modularized [7]. For ANSYS, users can program codes via Fortran or C languages, and the new element can be applied after it is compiled. The detailed procedure of UPFs is given as follows: (1) Copy the required documents to the specified working directory; (2) Open the specified documents with Visual Fortran, and then add user program, especially the element stiffness matrix; (3) Compile this program and connect it to ANSYS; (4) Activate UPFs with command line operation, and then the solid plate element with 8 nodes will be also activate automatically.

\section{Comparison with the fine analysis method of ANSYS}

Based on the parameters of stiffened plates with trapezoidal stiffeners above, the calculated results of the proposed method and ANSYS software are compared in Table 1.

Table 1 First 10 natural frequencies

\begin{tabular}{ccccc}
\hline \multirow{2}{*}{$\begin{array}{c}\text { Order of } \\
\text { frequency }\end{array}$} & \multicolumn{2}{c}{ Simply supported } & \multicolumn{2}{c}{ Clamped } \\
\cline { 2 - 5 } & ANSYS & $\begin{array}{c}\text { Proposed } \\
\text { method }\end{array}$ & ANSYS & $\begin{array}{c}\text { Proposed } \\
\text { method }\end{array}$ \\
\hline 1 & 38.54 & 38.65 & 64.86 & 64.93 \\
2 & 81.77 & 81.82 & 84.27 & 84.35 \\
3 & 83.02 & 83.13 & 84.56 & 84.62 \\
4 & 83.05 & 83.18 & 87.18 & 87.28 \\
5 & 83.86 & 83.98 & 87.74 & 87.86 \\
6 & 85.48 & 85.59 & 93.62 & 93.68 \\
7 & 86.62 & 86.68 & 93.86 & 93.89 \\
8 & 86.75 & 86.85 & 97.84 & 97.91 \\
9 & 89.81 & 89.94 & 102.69 & 102.71 \\
10 & 91.76 & 91.83 & 102.89 & 102.95 \\
\hline
\end{tabular}


From Table 1, it can be observed that the results of the proposed method are very close to those of ANSYS software under both simply supported and clamped boundary conditions, so this indicates the computation accuracy is much satisfactory when simulating deck pavement using solid plate element with 8 nodes. Meanwhile, the total amount of computation decreases, so this means the computation efficiency can increase.

\section{Conclusions}

This paper deals with the local dynamical behavior of steel box girder with stiffened plates on the basis of ANSYS software. During the analysis, solid plate element with 8 nodes is introduced to simulate deck pavement, and detailed process of this new element and its computational procedure are exhibited in this paper. By comparison with the fine analysis method of ANSYS through the first 10 natural frequencies of the stiffened plate corresponding to both simply supported and clamped boundary conditions, it shows the proposed method is not only accurate but also efficient, so this method can be generalized to engineering application.

\section{Acknowledgements}

This work was financially supported by the National Natural Science Foundation of China (51408228).

\section{References}

[1] H.X. Huang, K.N. Victor, C.J. Michael, et al. Application of Orthotropic Thin Plate Theory to Filled Steel Grid Decks for Bridges, Journal of Bridge Engineering, 12(2007): 807-810.

[2] British Standards Institution, BS5400-3 Steel, concrete and composite bridges: Code of practice for design of steel bridges, Britain, (2010).

[3] AASHTO, LRFD Bridge Design Specifications (5th Edition), Washington DC, (2010).

[4] K.M. Liew, L.X. Peng and S. Kitipornchai, Vibration Analysis of Corrugated Reissner-Mindlin Plates Using A Mesh-free Galerkin Method, International Journal of Mechanical Sciences, 51(2009): 642-652.

[5] L. Dozio and M. Ricciardi, Free Vibration Analysis of Ribbed Plates by a Combined Analytical-numerical Method, Journal of Sound and Vibration, 319(2009): 681-697.

[6] H.A. Xu, J.T. Du and W.L. Li, Vibrations of Rectangular Plates Reinforced by Any Number of Beams of Arbitrary Lengths and Placement Angles, Journal of Sound and Vibration, 329(2010): 3759-3779.

[7] W. Cheng, Collapse simulation analysis and program design of reinforced concrete structures based on ANSYS secondary development, Shanghai: Tongji University,( 2002). (In Chinese) 